\title{
SIR-B-The Second Shuttle Imaging Radar Experiment
}

\author{
JoBEA CIMINO, CHARLES ELACHI, SENIOR MEMBER, IEEE, AND MARK SETTLE
}

\begin{abstract}
On October 5, 1984, the second Shuttle Imaging Radar (SIR-B) was launched into orbit aboard the space shuttle Challenger. SIR-B is part of an evolutionary radar program designed to progressively develop a multifrequency, multipolarization synthetic aperture radar with a variable Earth-imaging geometry. The SIR-B instrument is an upgraded version of SIR-A, with the additional capability of tilting the antenna mechanically to acquire imagery at variable incidence angles ranging from $15^{\circ}$ to $60^{\circ}$. The variable look angle capability provided a means of acquiring multiple incidence angle imagery over specific targets on successive days of the mission. These data are being used to classify surface features by their backscatter signatures as a function of incidence angle and for topographic mapping. In addition to the antenna tilt capability, a digital data-handling system was added to increase the dynamic range, the resolution was improved by a factor of two over SIR-A, and a calibration subsystem was added to improve the radiometric accuracy of the data.

The mission had a number of problems, including loss of the primary digital data path between the shuttle and the ground. In spite of these problems, approximately 20 percent of the planned digital data were collected over the 8-day shuttle mission corresponding to an areal coverage of about 6.4 million $\mathrm{km}^{2}$.
\end{abstract}

\section{INTRODUCTION}

$\mathbf{J}^{\mathrm{sis}}$ UST BEFORE sunrise on October 5, 1984, the second Shuttle Imaging Radar, SIR-B, was launched into orbit aboard Challenger on mission 41-G. SIR-B was an upgraded version of SIR-A, which flew aboard Columbia on its second flight in November 1981. Both SIR-A and SIRB were $L$-band (23-cm wavelength) synthetic aperture radars with horizontal $(\mathrm{HH})$-polarization. SIR-A imaged the Earth at a constant look angle of $47^{\circ}$, and data were recorded and processed optically at a resolution of $40 \mathrm{~m}$ over a $50-\mathrm{km}$ swath. Improved capabilities added to the SIR-B system included a mechanically tilting antenna, a digital data-handling system, and a doubled bandwidth. The tilting antenna allowed imaging at selectable look angles between $15^{\circ}$ and $60^{\circ}$. This new capability provided a means of acquiring multiple-incidence angle imagery over selected targets on successive days of the mission. These data are being used to classify surface features by their backscatter signatures as a function of incidence angles and for stereotopographic mapping.

Manuscript received November 22, 1985; revised February 5, 1986. This work was supported by NASA's Office of Space Science and Applications.

J. B. Cimino and C. Elachi are with the Jet Propulsion Laboratory, Pasadena, CA 91109

M. Settle is with the ARCO Oil and Gas Co., Plano, TX 75075.

IEEE Log Number 8608571.

\section{Inheritance AND OBJectives}

The long-term goal of the evolutionary imaging radar program is to develop the scientific capability and the associated technology for a spaceborne multifrequency, multipolarization radar with variable imaging geometry in both incidence and azimuth angle that will fly on an extended mission of about 10 years on the Earth Observing System (Eos), the polar platform component of the Space Station. This goal is being accomplished by launching a series of spaceborne radars, each with a more expanded capability than the last. The program began in June, 1978 with the Seasat SAR, a free-flying Earth-orbiting synthetic aperture radar designed specifically to image the ocean [15], [1], [8], [7].

A fixed look angle of $20^{\circ}$ was chosen to provide the greatest sensitivity to subtle changes in the surface topography of the ocean. Seasat flew in a polar orbit at an inclination of $108^{\circ}$ and an altitude of $800 \mathrm{~km}$ allowing it to image both ocean and land surfaces. Seasat's power system failed unexpectedly in October 1978, thus ending its short 3.3-month lifetime. However, Seasat provided the first synoptic radar imagery of the Earth's surface. Not only was it a success technologically, but the imagery provided a new means of studying and observing the Earth's surface.

With the arrival of the shuttle, a new, easier means of developing advanced radar systems arose. With the shuttle, cheaper radars could be built and flown for short, proof-of-concept scientific missions and then returned to Earth where the hardware could be upgraded into progressively more advanced systems. Thus the radar program continued in 1981 with the launch of SIR-A aboard the second shuttle flight [2], [3], [6], [5]. The main objective of the SIR-A experiment was to acquire radar data over a variety of continental regions in order to further our understanding of the radar signatures of land features. A $47^{\circ}$ look angle was, therefore, selected to provide increased sensitivity to surface roughness and decreased sensitivity to topographic relief.

The SIR-A sensor operated nominally and the full data acquisition capacity of its optical recorder was used. Ten million square kilometers were imaged in the latitude range of $\pm 38^{\circ}$ over all continents except Antarctica during SIR-A's 2.5-day mission. One of the most exciting results of this experiment was the imaging of buried river channels in hyperarid regions of southern Egypt [12]. 


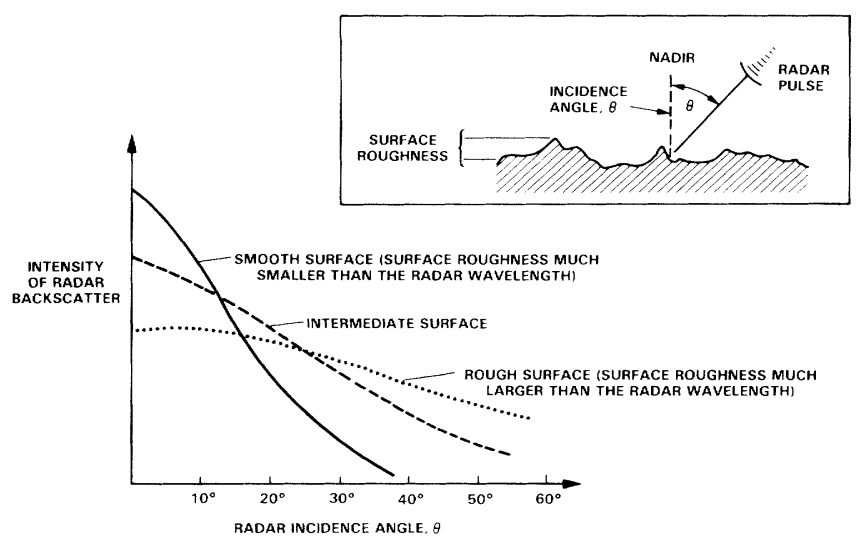

Fig. 1. Theoretical backscatter versus incidence angle response for surfaces with different roughnesses.

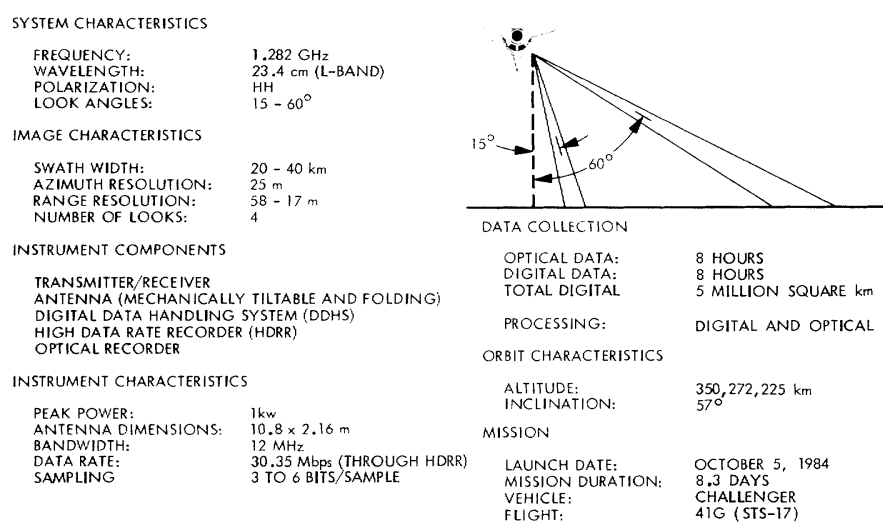

Fig. 2. The SIR-B system.

These channels are buried under 1-3 $\mathrm{m}$ of sand cover and are not visible on Landsat images or from the ground.

Seasat and SIR-A were fixed parameter sensors acquiring images at constant look angles (measured from nadir) of $20^{\circ}$ and $47^{\circ}$, respectively. A comparison of imagery acquired over the same area by each of these sensors demonstrated that the image intensity of various Earth surface features are functions of the incidence angle of the radar beam. In general, the response of the radar is controlled by topography at lower incidence angles and surface roughness (or the average size of rocks and vegetation relative to the radar wavelength) at larger incidence angles (Fig. 1). The rate at which radar backscatter decreases with increasing incidence angle is governed primarily by the roughness characteristics of the surface. Surfaces that are smooth relative to the wavelength of the radar will produce a steep backscatter curve while surfaces that are rough will produce a flatter Lambertian backscatter curve. At incidence angles greater than about $30^{\circ}$, a rougher surface will produce a stronger radar return than a smooth surface.

Quantifying the characteristic backscatter versus incidence angle response of various surfaces was the purpose of the SIR-B experiment (Fig. 2) [13], [2]. SIR-B was designed to image selected targets at a number of different incidence angles and use these angle-diversity data to determine the backscatter versus incidence angle character-

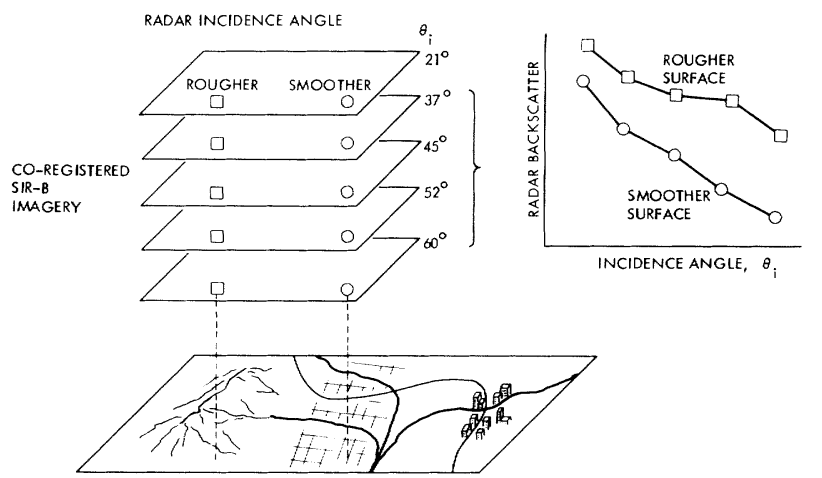

Fig. 3. Technique for classifying terrain types using the multiple incidence angle data collected with SIR-B

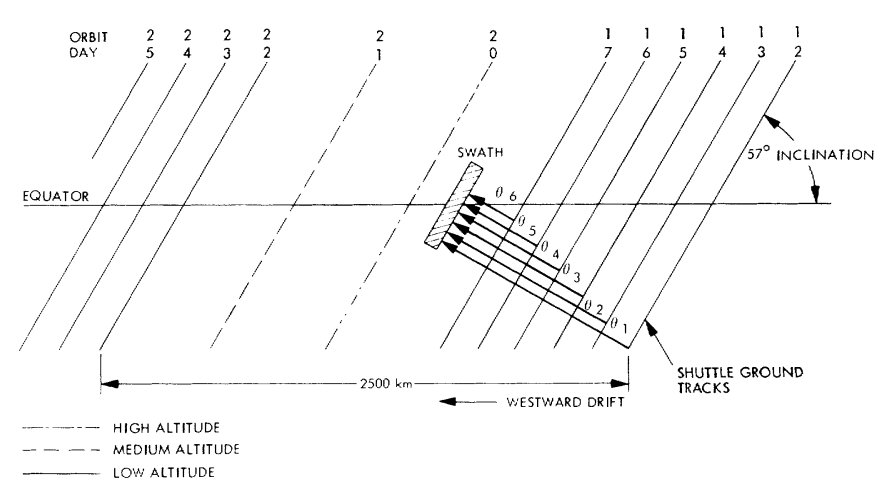

(a)

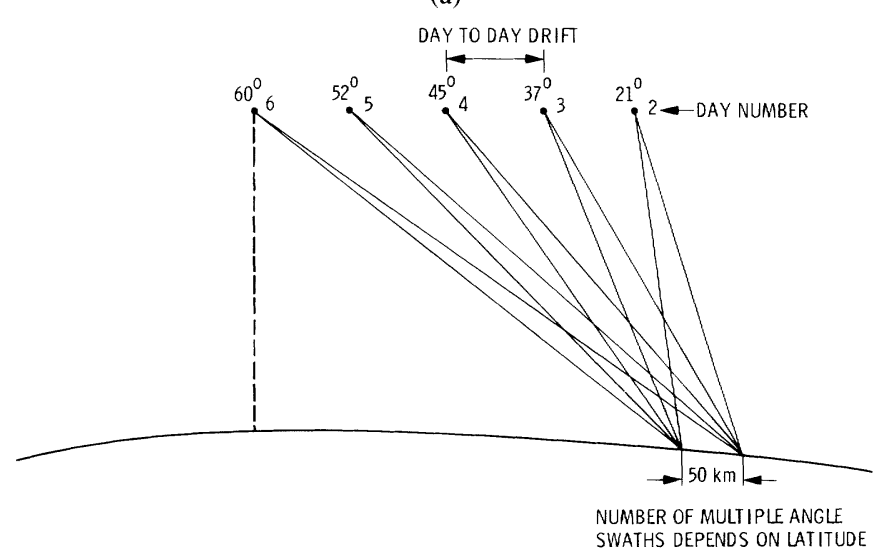

(b)

Fig. 4. The altitude of the SIR-B orbit was carefully selected to (a) produce a slight westward drift each day of the mission. (b) requiring a larger and larger incidence angle to image a specific target.

istics of various terrain types (Fig. 3). Earlier research had suggested that the backscatter characteristics of different natural surfaces could potentially be used to discriminate different types of terrain. To conduct this experiment, the SIR-B antenna was designed in such a fashion that it could be mechanically tilted in one-degree increments over a $15^{\circ}$ to $60^{\circ}$ range of look angles.

In order to acquire multiple-angle imagery with an orbiting radar, a very specific orbit altitude was selected. This altitude was almost that required for an exact oneday repeat cycle for the shuttle's ground track, however, it was raised slightly to produce a westward drift (Fig. 4(a)). Each day when the shuttle flew near a specific tar- 


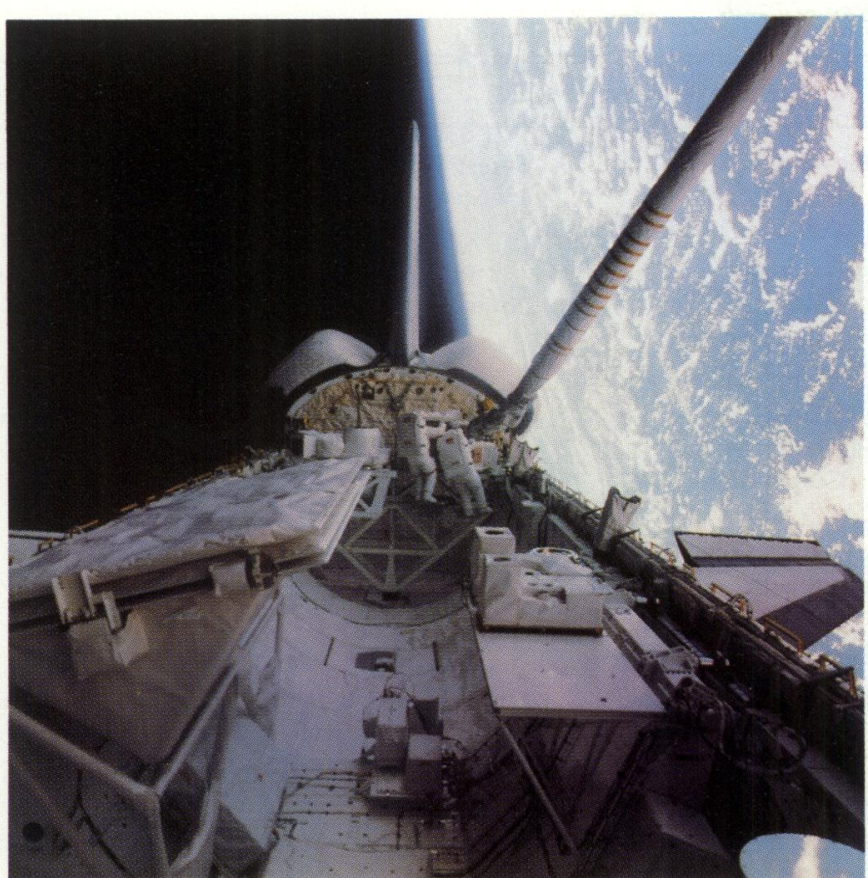

Fig. 5. Photograph taken by the crew of flight 41-G of SIR-B while in orbit.

get, it drifted farther and farther away requiring a larger and larger look angle to observe a target area (Fig. 4(b)). This pattern varied depending on the target latitude and longitude relative to the orbit node. It was also possible to use the orbital drift for stereoscopic imaging. Finally, by changing the incidence angle only slighty from day to day, laterally continguous images of large regions could be obtained and subsequently mosaiced together.

In addition to the variable look angle capability, SIR-B had a folding antenna (Fig. 5), an increased bandwidth, and a digital data system. The folding antenna provided more room in the shuttle payload for a deployable satellite, the Earth Radiation Budget Satellite (ERBS), to be carried into orbit. The increased bandwidth improved the range resolution by a factor of two. At a $47^{\circ}$ look angle, the resolution improved from $40 \mathrm{~m}$ on SIR-A to $20 \mathrm{~m}$ on SIR-B. The digital capability was included to allow quantitative, analytical studies of illumination effects on radar backscatter for the first time. The digital system also provided an improved dynamic range and the ability to improve the spatial resolution over that for SIR-A. The digital data system provided a choice of two data transmission routes: 1) through a Digital Data Handling System (DDHS) onboard the shuttle to the ground receiving station at White Sands, NM, via the Tracking and Data Relay System Satellite (TDRSS); or 2) through the DDHS to a 30-Mbit/s recorder mounted in the Challenger flight deck for later transmission via TDRS. The data were then sent via DOMSAT to Goddard Space Flight Center where they were recorded and later flown back to JPL for processing. The data rate through TDRSS for SIR-B was 46 Mbits/s, which could be handled in real time by the $\mathrm{Ku}-$ band 50-Mbits/s TDRSS link.
Two additional features were also added to enhance the flexibility of the SIR-B system and improve the final image product. First, the number of bits per sample was selectable from 3 to 6 . Inasmuch as the downlinked data rate was limited to $46 \mathrm{Mbits} / \mathrm{s}$ (TDRS real-time transmission) or $30 \mathrm{Mbits} / \mathrm{s}$ (onboard recording), it was possible to select fewer bits per sample in order to increase the swath width of the image or, alternately, to select more bits per sample for more dynamic range but a reduced swath. SIR$B$ also had an internal radiometric calibrator which would allow data to be calibrated over selected areas.

The SIR-B experiment was launched on the space shuttle Challenger into a nominally circular orbit at an inclination of $57^{\circ}$ and an average altitude of $360 \mathrm{~km}$ for the first 20 orbits, $235 \mathrm{~km}$ for the next 29 orbits, and $225 \mathrm{~km}$ for the duration of the 8.3-day mission. The $225-\mathrm{km}$ orbital altitude provided a one-day ground track repeat cycle with a westward drift each day allowing SIR-B to image a given site at a different incidence angle each day of the mission.

In order to acquire imagery on both the north and south side of the shuttle's nadir track, and to improve access to the TDRS satellite, the shuttle was flown in different attitudes. In the nose forward, payload bay to Earth $(-\mathrm{ZLV}$ or $-\mathrm{Z}$ local vertical), and the tail forward, starboarding wing to Earth attitudes, SIR-B could image on the northern side of the shuttle ground track. In the tail forward, $-\mathrm{ZLV}$, and nose forward, starboard wing to Earth attitudes, SIR-B could image to the south.

\section{THE EXPERIMENTS}

A team of 43 investigators participated in the SIR-B experiment. The SIR-B investigations include studies in the areas of geology, hydrology, vegetation, oceanography, and cartography, as well as studies on the characteristics of the radar system itself. These investigations were selected on their scientific merit and ability to take advantage of the unique characteristics of the SIR-B radar. Of those chosen, 13 were from foreign countries including Japan, Australia, Sweden, New Zealand, The Netherlands, Germany, England, and Canada. Many of the experiments proposed by U.S. investigators were carried out overseas in collaboration with foreign researchers. Collaborative data analysis programs of this nature were conducted in Egypt, Indonesia, Turkey, Argentina, Bangladesh, Botswana, India, Peru, Brazil, and Saudi Arabia. Two investigations were also carried out in foreign oceans-one along the Agulhas Current off the southeast coast of Africa and along the strong currents off the southwest coast of Chile, and the other in the South Atlantic Ocean off the coast of Antarctica. During the actual mission, some members of the SIR-B Science Team were positioned on ships and in airplanes, and in deserts, farms, and jungles around the world to collect ground truth data in support of their experiments.

These investigators and the titles of their experiments are listed in Table I along with their organizations and 
TABLE I

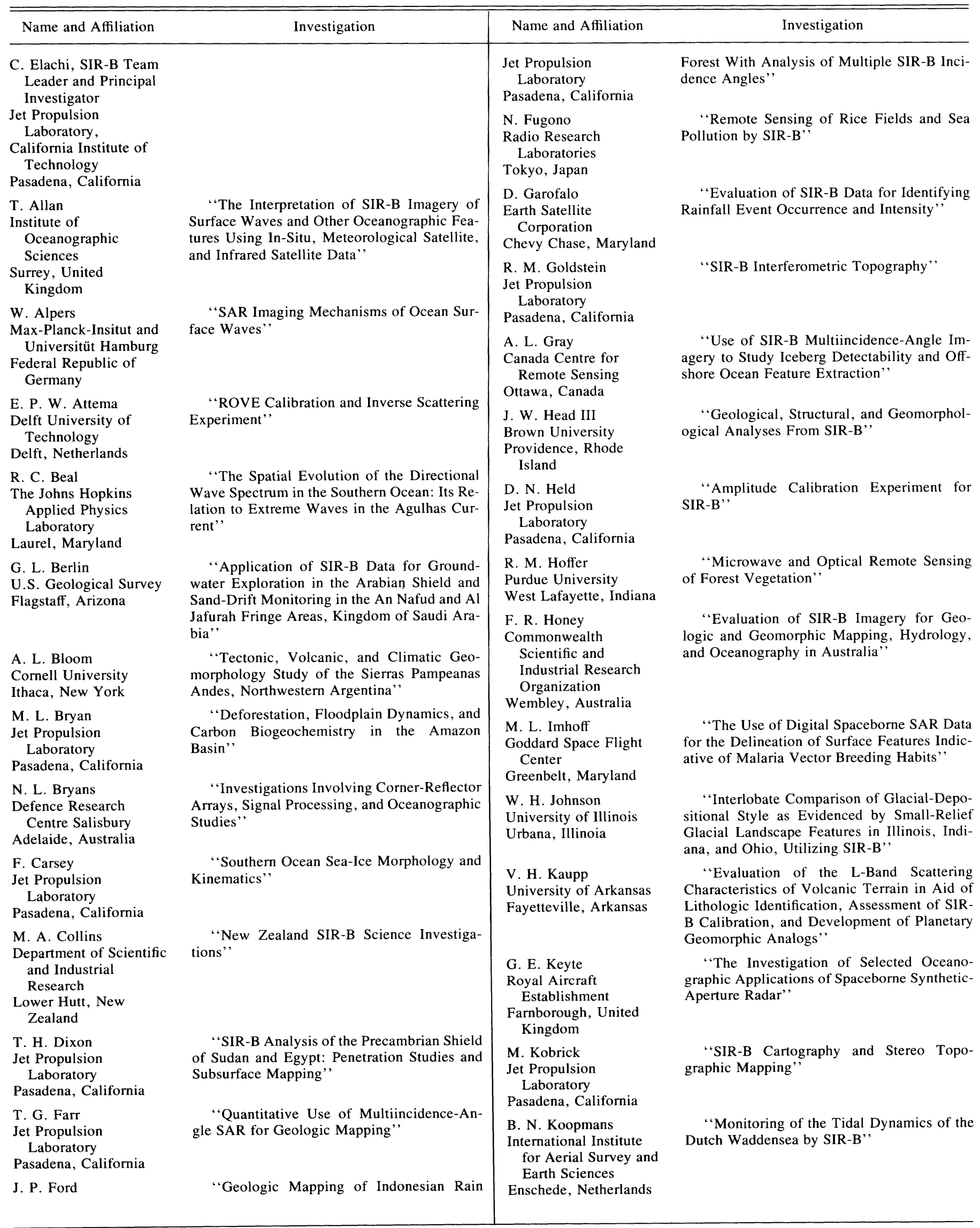


TABLE I (Continued)

\begin{tabular}{|c|c|c|c|}
\hline Name and Affiliation & Investigation & Name and Affiliation & Investigation \\
\hline $\begin{array}{l}\text { P. D. Lowman, Jr. } \\
\text { Goddard Space Flight } \\
\text { Center } \\
\text { Greenbelt, Maryland }\end{array}$ & $\begin{array}{l}\text { "Structural Investigation of the Canadian } \\
\text { Shield by Orbital Radar and Landsat" } \\
\text { "Structural Investigation of the Grenville } \\
\text { Province by Radar and Other Imaging and } \\
\text { Nonimaging Sensors"" }\end{array}$ & $\begin{array}{l}\text { D. S. Simonett } \\
\text { University of California } \\
\text { Santa Barbara, } \\
\quad \text { California } \\
\text { E. P. Szuszczewicz }\end{array}$ & $\begin{array}{l}\text { "The Extension of an Invertible Conifer- } \\
\text { ous Forest Canopy Reflectance Model Using } \\
\text { SIR-B and Landsat Data" } \\
\text { "An Investigation of Ionospheric Irregular- }\end{array}$ \\
\hline $\begin{array}{l}\text { R. K. Moore } \\
\text { University of Kansas } \\
\text { Center for Research, }\end{array}$ & $\begin{array}{l}\text { "Studies of Coastal Mesoscale Winds } \\
\text { Using SIR-B", } \\
\text { "Information for Space-Radar Designers: }\end{array}$ & $\begin{array}{l}\text { Naval Research } \\
\text { Laboratory } \\
\text { Washington, D.C. }\end{array}$ & $\begin{array}{l}\text { ity Effects on SIR-B Image Processing and In- } \\
\text { formation Extraction". }\end{array}$ \\
\hline $\begin{array}{l}\text { Inc. } \\
\text { Lawrence, Kansas }\end{array}$ & $\begin{array}{l}\text { Required Dynamic Range vs Resolution and } \\
\text { Antenna Calibration Using the Amazon Rain } \\
\text { Forest" } \\
\text { "'Development and Evaluation of Tech- }\end{array}$ & $\begin{array}{l}\text { J. V. Taranik } \\
\text { University of Nevada } \\
\text { Reno, Nevada }\end{array}$ & $\begin{array}{l}\text { "Analysis of SIR-B Radar Illumination Ge- } \\
\text { ometry for Depth of Penetration and Surface } \\
\text { Feature and Vegetation Detection, Nevada and } \\
\text { California", }\end{array}$ \\
\hline $\begin{array}{l}\text { J. F. Paris } \\
\text { Jet Propulsion } \\
\text { Laboratory } \\
\text { Pasadena, California }\end{array}$ & $\begin{array}{l}\text { "Development and Evaluation of Tech- } \\
\text { niques for Using Combined Microwave and } \\
\text { Optical Image Data for Vegetation Studies"" }\end{array}$ & $\begin{array}{l}\text { M. N. Toksoz } \\
\text { Massachusetts Institute } \\
\text { of Technology }\end{array}$ & $\begin{array}{l}\text { California"' } \\
\text { " Delineation of Major Geologic Structures } \\
\text { in Turkey Using SIR-B Data" }\end{array}$ \\
\hline $\begin{array}{l}\text { J. T. Parr } \\
\text { The Analytic Sciences } \\
\text { Corporation } \\
\text { Reading, Massachusetts } \\
\text { H. K. Ramapriyan } \\
\text { Goddard Space Flight } \\
\text { Center } \\
\text { Greenbelt, Maryland }\end{array}$ & $\begin{array}{l}\text { "Investigation of SIR-B Images for Lith- } \\
\text { ologic Mapping", }\end{array}$ & $\begin{array}{l}\text { Cambridge, } \\
\text { Massachusetts } \\
\text { F. T. Ulaby } \\
\text { University of Kansas } \\
\text { Center for Research, } \\
\text { Inc. } \\
\text { Lawrence, Kansas } \\
\text { P. }\end{array}$ & $\begin{array}{l}\text { "Evaluation of the Radar Response to Land } \\
\text { Surfaces and Volumes: Examination of Theo- } \\
\text { retical Models, Target Statistics, and Appli- } \\
\text { cations" }\end{array}$ \\
\hline $\begin{array}{l}\text { J. A. Richards } \\
\text { University of New } \\
\text { South Wales } \\
\text { Kensington, Australia }\end{array}$ & $\begin{array}{l}\text { "Australian Multiexperimental Assess- } \\
\text { ment of SIR-B (AMAS)" }\end{array}$ & $\begin{array}{l}\text { P. Ulriksen } \\
\text { Lund University of } \\
\text { Technology } \\
\text { Lund, Sweden } \\
\text { J. R. Wang }\end{array}$ & $\begin{array}{l}\text { "Ground Truth for SIR-B Images Obtained } \\
\text { by SIR System } 8 \text { Impulse Radar" }\end{array}$ \\
\hline $\begin{array}{l}\text { G. G. Schaber } \\
\text { U.S. Geological Survey } \\
\text { Flagstaff, Arizona }\end{array}$ & $\begin{array}{l}\text { "Application and Calibration of the Sub- } \\
\text { surface Mapping Capability of SIR-B in De- } \\
\text { sert Regions", }\end{array}$ & $\begin{array}{l}\text { Goddard Space Flight } \\
\text { Center } \\
\text { Greenbelt, Maryland }\end{array}$ & \\
\hline $\begin{array}{l}\text { A. J. Sieber } \\
\text { Deutsche Forschungs- } \\
\text { und Versuchsanstalt } \\
\text { für Luft- und } \\
\text { Raumfahrt } \\
\text { Federal Republic of } \\
\text { Germany }\end{array}$ & $\begin{array}{l}\text { "German Radar Observation Shuttle Ex- } \\
\text { periment (ROSE)" }\end{array}$ & $\begin{array}{l}\text { R. S. Winokur } \\
\text { Office of Naval } \\
\text { Research } \\
\text { Arlington, Virginia }\end{array}$ & $\begin{array}{l}\text { "SAR Internal Wave Signature Experi- } \\
\text { ment"' }\end{array}$ \\
\hline
\end{tabular}

countries. A detailed description of the experiments is given in "The SIR-B Science Investigations Plan," 1984.

\section{Mission Problems}

A number of problems occurred during the SIR-B mission that prevented acquisition of the complete set of planned imagery. The first problem occurred on the first day of the mission after the first SIR-B data take. The $\mathrm{Ku}$ band antenna that was used to transmit digital data to the TDRS relay satellite lost its drive mechanism. It began oscillating from side to side making it impossible to track TDRSS. The problem was partially remedied by disconnecting the antenna pointing control and locking the $\mathrm{Ku}$ band antenna in a fixed position so that the power could be applied without creating the oscillations. In this locked position, the entire shuttle had to be maneuvered in order to transmit digital SIR-B data to the ground. The new mode of operation for SIR-B then was to acquire $20 \mathrm{~min}$ of data on the onboard tape recorder, and then put the shuttle in its TDRSS tracking attitude. Under these circumstances, the total planned data had to be cut by about 80 percent, thus allowing only $8 \mathrm{~h}$ of data acquisition versus the $40 \mathrm{~h}$ orginally planned.
A second problem resulted in a loss of about $16 \mathrm{~dB}$ round trip ( $8 \mathrm{~dB}$ of return signal power) in the antenna feed. A particle in the antenna feed cable was causing arching resulting in a transmitted power that was $8 \mathrm{~dB}$ less than planned. A corresponding loss of $8 \mathrm{~dB}$ was encountered when the return signal was transmitted back through the antenna. Because of the dynamic range available in the digital data system, it was possible in most cases to boost the gain to partially compensate for this loss in power.

In spite of these problems, a large number of SIR-B targets were imaged sucessfully. Sufficient data were acquired to demonstrate the value of the multiple-angle capability. The final data set (Fig. 6) consists of about $8 \mathrm{~h}$ of digital data covering about 6.4 million $\mathrm{km}^{2}$ of the Earth's surface.

Two types of multiple-incidence angle experiments were accomplished on the SIR-B flight. A stereoanalysis was made to determine the optimum pair of incidence angle images for generating topographic maps [10], [11]. The digital elevation model generated for the Mt. Shasta, California, region was used to generate perspective views of the mountain (Fig. 7(a)). Displaying radar imagery 


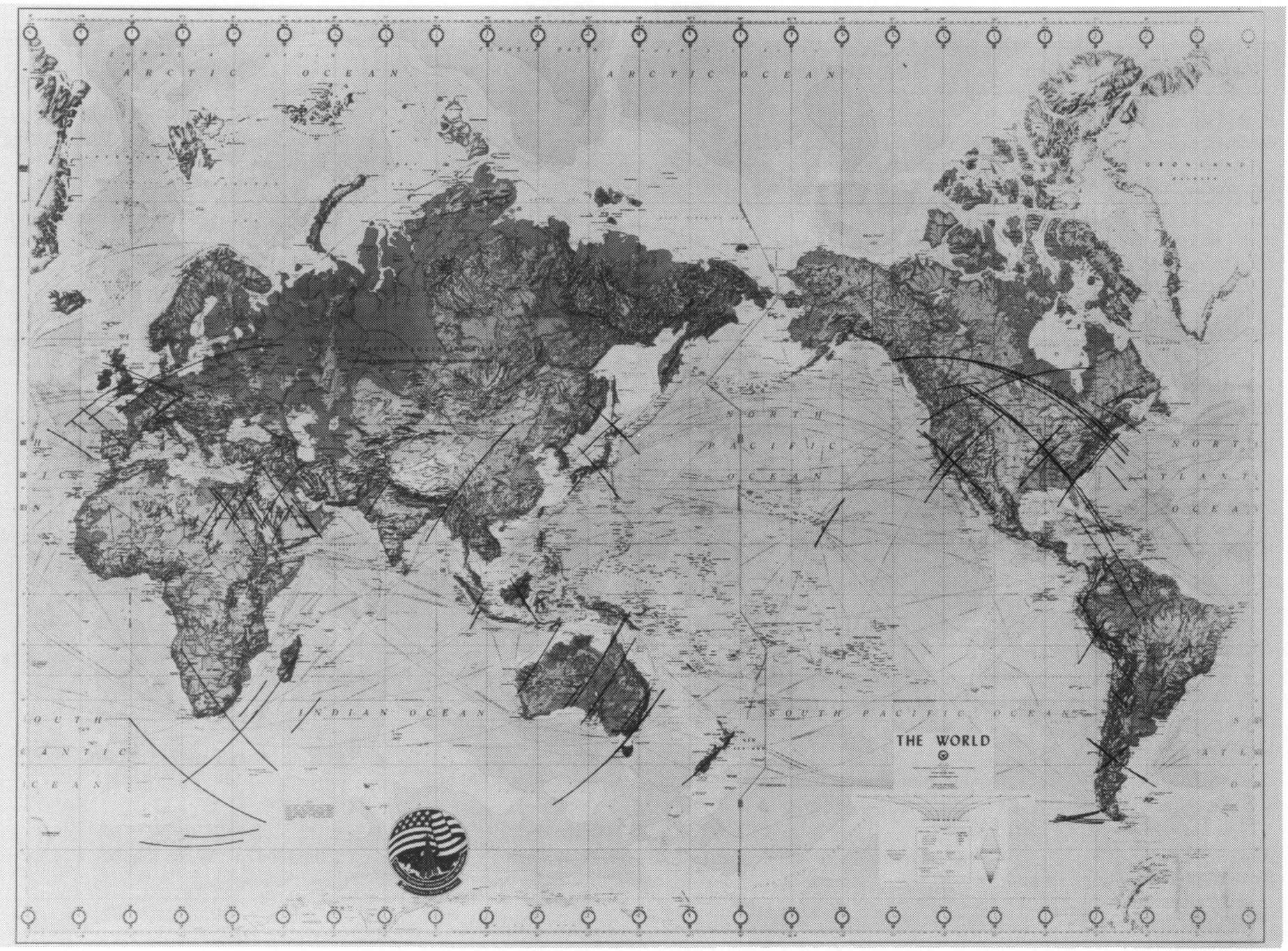

Fig. 6. Digital data set coverage acquired by SIR-B.

from various perspectives is a useful tool for structural geologic mapping. Also, an assessment of the potential for classifying various forest stands using the backscatter signatures as a function of incidence angle was done in the northern Florida region [9]. To visually assess the response of forest stands to radar of different incidence angles, a color composite was generated. The SIR-B image acquired at the steepest incidence angle was colored blue, the one acquired at a medium incidence angle, green, and the one at the highest incidence angle, red (Fig. 7(b)). The color composite displays the forest stands in a variety of colors, indicating that indeed the response of trees to incoming radiation at different incidence angles can be used to classify the stands.

\section{Future Plans}

The data collected during the SIR-B mission illustrate the utility of using multiple incidence angle images to classify terrain types. The next step in the evolutionary radar program is SIR-C. Both a multifrequency and multipolarization capability will be included. SIR-C will add a $C$-band system to SIR-B's $L$-band system and will add the capability to transmit and receive any combination of horizontally and vertically polarized signals. An $X$-band channel will also be supplied by the German Aerospace Research Establishment (DFVLR). Present plans call for two SIR-C missions to occur in different seasons in 1990. SIR-C will be designed such that, with minor modifications, it can be flown aboard the Earth Observing System (Eos) polar platform (Eos Science and Mission Requirements Working Group Report, 1984). The Eos SAR will for the first time have the capability to collect 9 channels of SAR data simultaneously (all three frequencies at all three combinations of polarization), collect long time sequences of SAR data, do extensive mapping over large areas (e.g., the entire Egyptian desert), and collect data simultaneously with visible, infrared, and passive microwave systems.

\section{ACKNOWLEDGMENT}

As in every major experiment involving complicated sensors, success results from a team effort involving numerous people. We would like to acknowledge our colleagues at JPL and JSC who designed, developed, tested, and operated the SIR-B sensor. In particular, we acknowledge the efforts of E. Caro (Task Manager), B. Huneycutt 


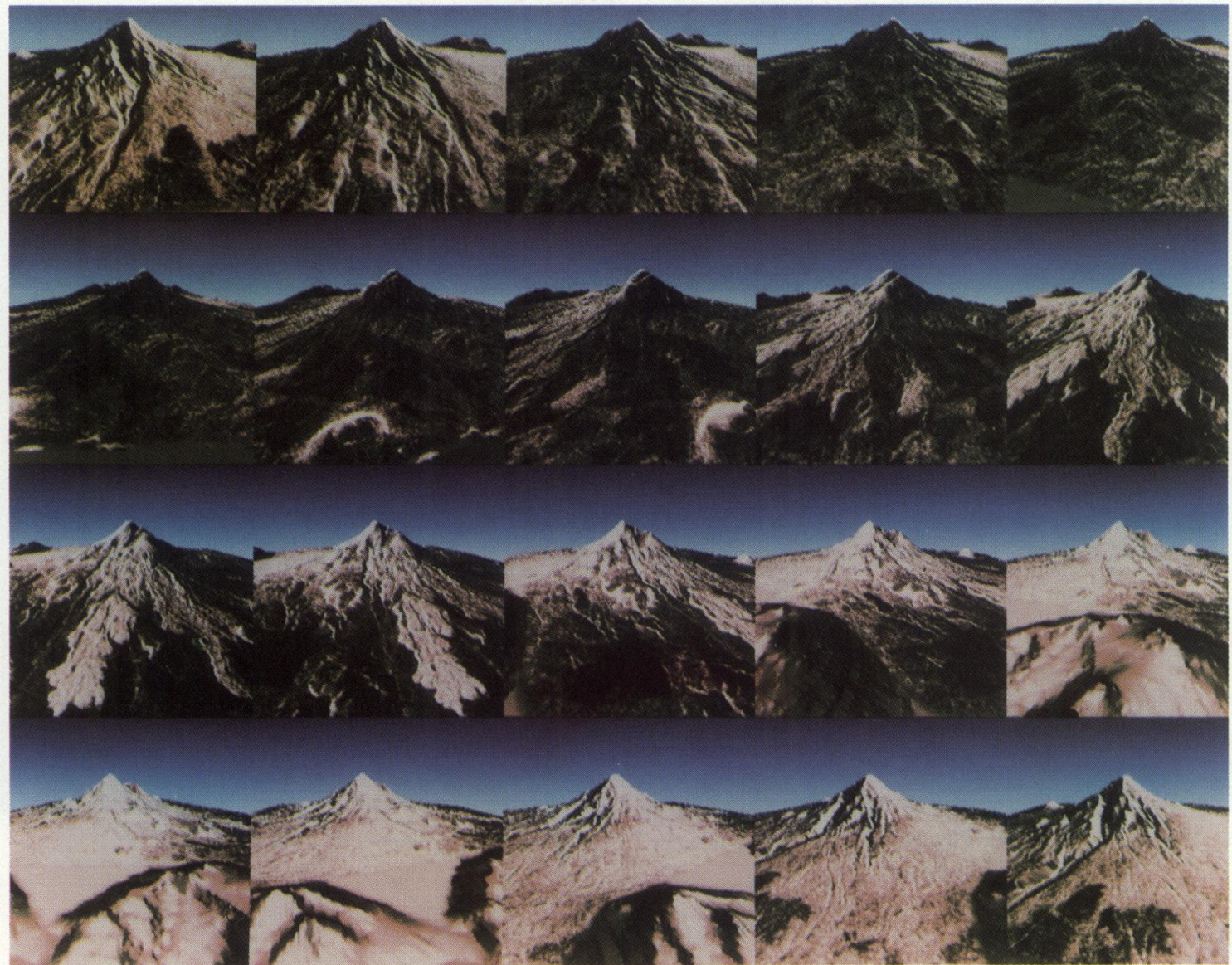

(a)

Fig. 7. (a) Perspective views of Mt. Shasta, CA, generated using a digital elevation model determined from a stereo pair of SIR-B images. All information displayed in the scenes was generated from SIR-B imagery. (Fig. 7(b) is on page 452.)

(Cognizant Engineer), S. Wall, J. Curlander, M. Ruzek, B. Holt, and numerous other people at JPL who were part of the SIR-B implementation and operation team. We would like to acknowledge the support of the many people at JSC, particularly R. Baldwin, L. Godwin, H. Nitschke and the 41-G crew, and at NASA Headquarters, particularly S. Tilford, R. Monson, and L. Demas.

\section{REFERENCES}

[1] R. C. Beal, P. S. DeLeonibus, and I. Katz, Eds., Spaceborne Synthetic Aperture Radar for Oceanography. Baltimore, MD: Johns Hopkins Univ. Press, 1982

[2] J. B. Cimino and C. Elachi, Eds., "The shuttle imaging radar-A (SIRA) experiment," Jet Propulsion Laboratory, Pasadena, CA, JPL Pub. 82-77.

[3] — "The SIR-B radar on the shuttle ," in Proc. 2nd Thematic Conf.: Remote Sensing for Exploration Geology (Fort Worth, TX), 1982.

[4] J. B. Cimino, A. Brandani, D. Casey, J. Rabassa, and S. Wall, "Multiple incidence angle SIR-B experiment over Argentina: Mapping of forest units," IEEE Trans. Geosci. Remote Sensing, this issue, pp. 498-509.

[5] C. Elachi, W. E. Brown, J. B. Cimino, T. Dixon, D. L. Evans, J. P. Ford, R. S. Saunders, C. Breed, H. Masursky, J. F. McCauley, G. Schaber, L. Dellwig, A. England, H. MacDonald, P. Martin-Kaye, and F. Sabins, "Shuttle imaging radar experiment," Science, vol. 218, pp. 996-1003, 1982.
[6] J. Ford J. B. Cimino, and C. Elachi, "Space shuttle Columbia views the world with imaging radar: The SIR-A experiment," Jet Propulsion Laboratory, Pasadena, CA, JPL Pub. 82-95, 1982.

[7] J. P. Ford et al., "Seasat views North America, the Carribean and Western Europe with imaging radar," Jet Propulsion Laboratory, Pasadena, CA, JPL Pub. 80-67.

[8] L. Fu and B. Holt, "Seasat views oceans and sea ice with synthetic aperture radar," Jet Propulsion Laboratory, Pasadena, CA, JPL Pub. 81-120, 1980.

[9] R. M. Hoffer, P. W. Mueller, and D. F. Lozano-Garcia, "Use of multiple incidence angle shuttle imaging radar data for identifying forest cover,' ' in preparation.

[10] F. Leberl, G. Domik, J. Raggam, and M. Kobrick, "Radar stereomapping techniques and application to SIR-B images of Mt. Shasta,' IEEE Trans. Geosci. Remote Sensing, this issue, 473-481.

[11] F. Leberl, G. Domik, J. Raggam, J. B. Cimino, and M. Kobrick, "Multiple incidence angle SIR-B experiment over Argentina: Stereoradargrammetric analysis,' IEEE Trans. Geosci. Remote Sensing, this issue, p. 482-491.

[12] J. F. McCauley, G. G. Schaber, C. S. Breed, M. J. Grolier, C. U. Haynes, B. Issawi, C. Elachi, and R. Blom, "Subsurface valleys and geoarcheology of the eastern Sahara revealed by Shuttle radar," Science, vol. 218, pp. 1004-1019, 1982.

[13] “'The SIR-B science plan," Jet Propulsion Laboratory, Pasadena, CA. JPL Pub. 82-78, 1982.

[14] "The SIR-B science investigations plan," Jet Propulsion Laboratory, Pasadena, CA, JPL Pub. 83-3, 1984.

[15] J. Vesecky and R. Stewart "The observation of ocean surface phenomena using imagery from the seasat synthetic aperture radar: An assessment," J. Geoph. Research, vol. 87, pp. 3397-3430, 1982. 


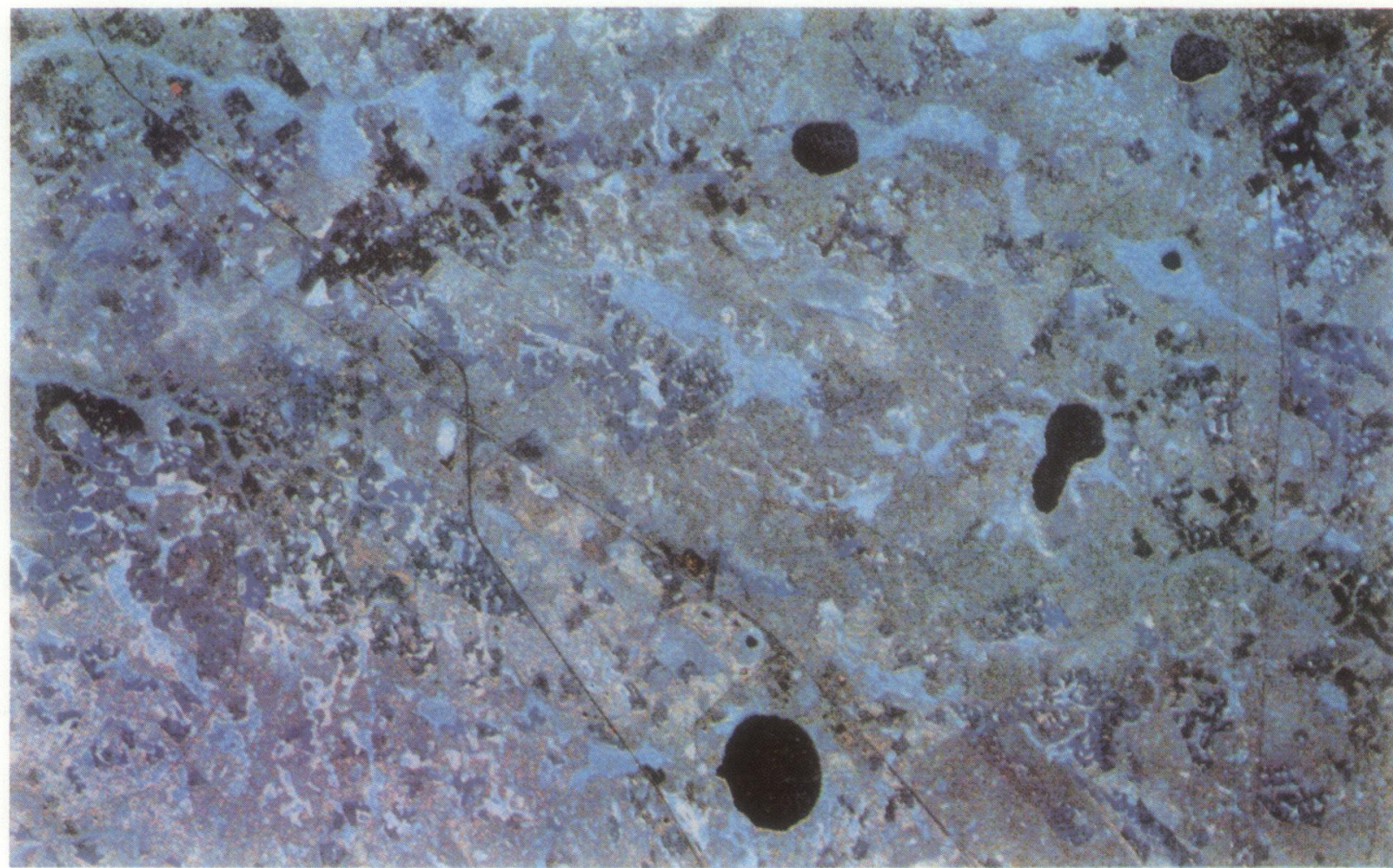

\section{CENTER}

$\begin{array}{ll}\text { RED: } & 58.3^{\circ} \\ \text { GREEN: } & 45.3^{\circ} \\ \text { BLUE: } & 28.4^{\circ}\end{array}$

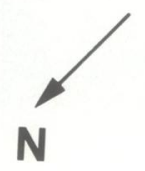

$10 \mathrm{~km}$

Fig. 7. (b) Color composite of the Ocean Pond, Florida region, generated using a set of three multiple incidence angle SIR-B images. The region is composed of a variety of forest stands which can be distinguished by their radar backscatter signatures.

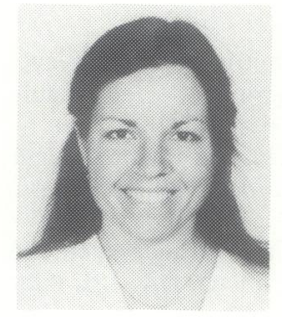

JoBea Cimino was born in Lorrain, $\mathrm{OH}$, in 1954 She received the B.S. degree in chemistry from the University of California at Berkeley, and the M.S. and Ph.D. degrees in planetary science from the California Institute of Technology, Pasadena, in 1978 and 1981, respectively.

At the Jet Propulsion Laboratory, she is the Experiment Scientist for the Shuttle Imaging Radar, SIR-B, and the radar which will fly on the Space Station's Earth Observing System. She is leading a study using multiple incidence and multiple azimuth angle SIR-B data collected over Argentina to understand the effects of imaging geometry on radar backscatter.

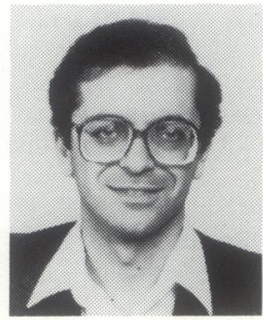

Charles Elachi (M'71-SM'82) was born in Lebanon in 1947. He received the Ingenieur degree with honors in radioelectricity and the "Prix de la Houille Blanche" from the Polytechnic Institute of Grenoble, Grenoble, France, in 1968 and the B.S. degree in physics from the University of Grenoble in 1968. He received the M.S. and Ph.D. degrees in electrical sciences from the California Institute of Technology, Pasadena, in 1969 and 1971 , respectively.

$\mathrm{He}$ has worked at the Physical Spectrometry Laboratory, University of Grenoble, France, on plasma in microwave cavities. He was a Teaching Assistant at the California Institute of Technology in 1969. In 1970, he joined the Space Sciences Division, Jet Propulsion Laboratory, Pasadena, where he is presently Division Manager and a Senior Research Scientist involved in investigating spacecraft-borne scientific experiments for planetary and Earth studies using coherent radar tech- niques. Since 1980, he has been the Manager for Radar Development, which covers all aspects of the radar remote-sensing program at JPL. He was the Principal Investigator on the Shuttle Imaging Radar (SIR-A) which flew in 1981, and the follow-on SIR-B experiment (1984). He is the Project Scientist of the SIR project and a Team member on the Magellan (Venus Radar Mapper) mission. He has been involved in studying theoretical electromagnetic problems related to scattering from natural terrain, remote sensing, stratified media, space-time periodic media, and DFB lasers. He has 170 papers, patents, reports, and conference presentations in the above fields. He also lectures at the California Institute of Technology on the "Physics of Remote Sensing.",

In 1973, Dr. Elachi was the first recipient of the R.W.P. King award. In 1980 and 1982 he received the Autometric Award of the American Phogrammetric Society. In 1982 he received the NASA Exceptional Scientific Achievement Medal and, in 1985, the W. T. Pecora award.

$*$

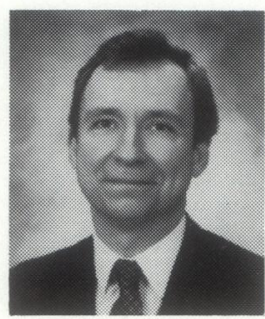

Mark Settle (M'82) received the B.S. and M.S. degrees in geology from the Massachusetts Institute of Technology, Cambridge. He received the $\mathrm{Ph} . \mathrm{D}$. degree in geology from Brown University, Providence, RI, in 1979.

$\mathrm{He}$ is currently the Director of the Exploration Techniques Group at ARCO's Exploration and Production Research Center in Plano, TX. In this capacity, he is responsible for developing improved surface reconnaissance techniques for evaluating hydrocarbon potential. Prior to joining ARCO in 1984, he was the Manager of the Geological Applications Program within the Office of Space and Terrestrial Applications at NASA Headquarters. 